\title{
Metal/Carbon-Fiber Hybrid Composites-Damage Evolution and Monitoring of Isothermal Fatigue at Low and Elevated Temperatures
}

\author{
Bilal Khatri ${ }^{1, * \mathbb{D}}$, Jan Rehra ${ }^{2}$, Sebastian Schmeer ${ }^{2}\left(\mathbb{D}\right.$, Ulf Breuer ${ }^{2}$ and Frank Balle ${ }^{1,3}(\mathbb{D}$ \\ 1 Walter and Ingeborg Herrmann Chair for Power Ultrasonics and Engineering of Functional Materials, \\ Department of Sustainable Systems Engineering (INATECH), University of Freiburg, \\ 79110 Freiburg, Germany; frank.balle@inatech.uni-freiburg.de \\ 2 Leibniz-Institut für Verbundwerkstoffe (IVW), Technische Universität Kaiserslautern, \\ 67663 Kaiserslautern, Germany; jan.rehra@ivw.uni-kl.de (J.R.); sebastian.schmeer@ivw.uni-kl.de (S.S.); \\ ulf.breuer@ivw.uni-kl.de (U.B.) \\ 3 Freiburg Materials Research Center (FMF), 79110 Freiburg, Germany \\ * Correspondence: bilal.khatri@inatech.uni-freiburg.de
}

check for updates

Citation: Khatri, B.; Rehra, J.;

Schmeer, S.; Breuer, U.; Balle, F. Metal/Carbon-Fiber Hybrid

Composites-Damage Evolution and

Monitoring of Isothermal Fatigue at

Low and Elevated Temperatures. J.

Compos. Sci. 2022, 6, 67. https://

doi.org/10.3390/jcs6030067

Academic Editor: Konda Gokuldoss Prashanth

Received: 31 January 2022

Accepted: 17 February 2022

Published: 23 February 2022

Publisher's Note: MDPI stays neutral with regard to jurisdictional claims in published maps and institutional affiliations.

Copyright: () 2022 by the authors. Licensee MDPI, Basel, Switzerland. This article is an open access article distributed under the terms and conditions of the Creative Commons Attribution (CC BY) license (https:// creativecommons.org/licenses/by/ $4.0 /)$.

\begin{abstract}
Carbon-fiber-reinforced polymers (CFRPs) are the standard lightweight composite material for structural applications in aviation. The addition of metallic fibers to CFRPs to form metal/carbonfiber hybrid composites (MCFRPs) has been shown to improve the elastic and plastic properties and to enable a non-destructive method for structural health monitoring over the material's service life. In this paper, the results from the fatigue experiments on these hybrid composites at $-55,25$ and $120^{\circ} \mathrm{C}$ are discussed. Multidirectional CFRP and MCFRP laminates, fabricated using the autoclave method, were tested and compared under different fatigue loading conditions, while being simultaneously monitored for temperature and electrical resistance. Magnetic phase measurements were additionally carried out for the chosen metastable austenitic steel fibers in the MCFRPs. The results show that the improved ductility of the hybrid composite due to the presence of the steel fibers leads to better performance under fatigue loads and a less-brittle failure behavior. Based on the chemical composition of the metastable austenitic steel fibers, a temperature and plastic deformation-dependent phase transformation was observed, which could potentially lead to a method for non-destructive structural health monitoring of the hybrid composite over its service life.
\end{abstract}

Keywords: hybrid composites; fatigue in composites; structural health monitoring

\section{Introduction}

Carbon-fiber-reinforced polymers (CFRP) have, in the last few decades, evolved to become the primary load-bearing material in modern aircraft, comprising over $50 \mathrm{wt} . \%$ of the fuselage mass in aircraft, such as the Boeing 787 and the Airbus A350 [1]. Compared to lightweight metals, such as aluminum, CFRPs exhibit comparable stiffness with a superior strength-to-density ratio and a distinctly lower fatigue onset.

At the same time, these composites exhibit limited damage tolerance, impact tolerance and a brittle failure behavior, as well as poor electrical conductivity opposite to their metallic counterparts. A number of important aircraft functions, such as lightning-strike protection, grounding, electromagnetic shielding and signal transfer, can only be realized for CFRP-based fuselages by the addition of metallic components, such as copper foils, wires and cables, causing an increase in the process complexity and time. Moreover, these additional masses do not contribute to the structural properties and are a limiting factor in the cumulative strength-to-density ratio of the fuselage.

The majority of these functions depend on the electrical properties of CFRP. Studies have looked at modifications in the matrix system to improve the electrical conductivity 
of the composite through the addition of carbon nanotubes [2,3]. A comparable level of electrical conductivity to that of aluminum fuselages through modifications of the matrix has thus far not been attained.

Through the integration of metal fibers in CFRPs, the advantages of both metals and carbon fibers can potentially be combined. Hybrid composites have been demonstrated in the case of glass-fiber/CF composites [4,5], which show improved ductility. The use of metallic sheets or foils is established for fiber-metal laminates, such as GLARE [6], whereas the addition of steel fibers to a polymer matrix has been shown to combine high stiffness and ductility $[7,8]$, enabling the tailoring of the composites' constituents to the mass, stiffness and ductility requirements. A number of studies and reviews from the past four years have looked at metal/CF hybrid composites as sandwich panels, from manufacturing and processing $[9,10]$ to their mechanical [11-13] and damage initiation and evolution [14] characteristics.

By integrating metal fibers and carbon fibers into so-called metal/carbon-fiber hybrid composites (MCFRPs), the mechanical and electrical properties can be tailored by modifying the laminate layup and through the fiber fraction of the metal and carbon fibers. A pronounced improvement in the electrical conductivity through the integration of stainless steel fibers has been reported in recent studies $[15,16]$. One of these also analytically modeled the failure behavior of steel-fiber and carbon-fiber composites [17].

In a preceding study, MCFRPs with integrated stainless steel fibers were analyzed for their fatigue behavior and failure mechanisms at room temperature [18]. Through the use of metastable austenitic steel fibers, a potential non-destructive structural health monitoring (SHM) system was demonstrated. This relies on the deformation-dependent austenite-martensite phase transformation of the steel fibers, which causes the metal to respond to plastic deformation through a measurable magnetic response.

This response can, in turn, be correlated with the progressive damage done to the material under fatigue conditions. This work expands upon the topic by characterizing the MCFRPs at aviation-grade temperatures, i.e., -55 and $120^{\circ} \mathrm{C}$, while also comparing the mechanical and electrical characteristics MCFRPs against similarly fabricated CFRP laminates. The temperature-dependency of the austenite-martensite phase transition due to plastic deformation under fatigue loading is also presented.

\section{Intrinsic Structural Health Monitoring}

Metastable austenitic stainless steel fibers in the MCFRPs can, in addition to improving the electrical properties of the composite, provide a non-destructive method for gauging damage due to fatigue over the hybrid material's service life. Through the combination of temperature and plastic deformation, the metastable austenitic steel can undergo a phase transformation into the magnetically responsive martensite. This temperature-dependent, deformation-driven austenite-martensite phase transformation of stainless steel can be explained through its Gibbs free energy diagram $[19,20]$, which is illustrated in Figure 1.

Above the thermodynamic equilibrium temperature $T_{0}$, the favored structure of a given stainless steel is $\gamma$-austenite due to its lower Gibbs free energy $\mathrm{G}_{\gamma}$. With decreasing temperature, the probability of the martensitic transformation increases, owing to the increasing free energy difference between $\mathrm{G}_{\gamma}$ and $\mathrm{G} \alpha^{\prime}$, shown in Figure 1 as $\Delta \mathrm{G}_{\mathrm{chem}}$. For a given chemical composition of the steel, the martensite start temperature $\left(\mathrm{M}_{\mathrm{s}}\right)$ represents the point below which the temperature-driven martensitic transformation can occur $\Delta \mathrm{G}_{\min }^{\gamma \rightarrow \alpha}$.

When undergoing plastic deformation, the additional mechanical energy $\left(\Delta \mathrm{G}_{\text {mech }}\right)$ coming into the system results in an increased free energy difference between the deformed austenite phase $\left(G_{\gamma}{ }^{\prime}\right)$ and that of the austenite phase $\left(G_{\alpha}{ }^{\prime}\right)$ at a given temperature. This greater difference increases the probability of the $\gamma \rightarrow \alpha^{\prime}$ transformation to occur at a temperature higher than $M_{s}$, referred to here as the martensite deformation temperature $M_{d}$. 


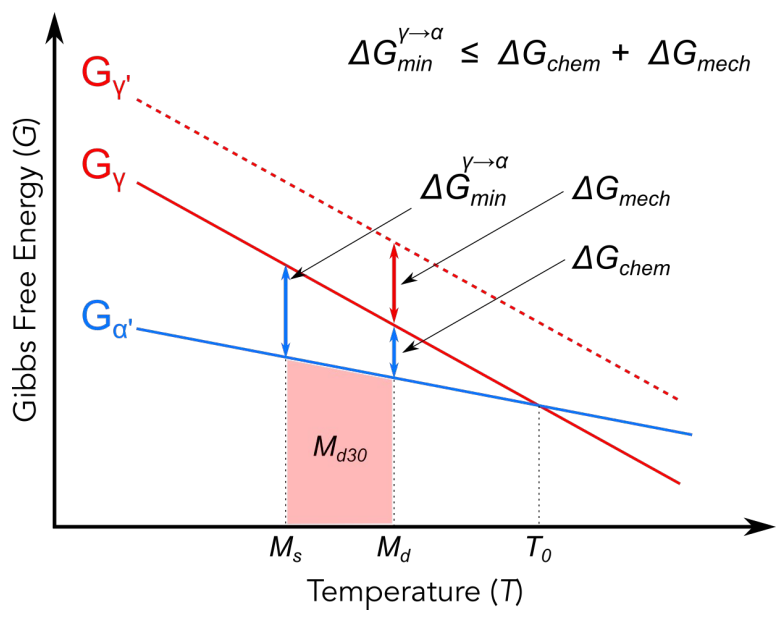

Figure 1. The austenite-martensite phase transformation in steels as a function of temperature and plastic deformation. Adapted from $[19,20]$.

As $M_{s}$ and $M_{d}$ are both difficult to determine experimentally, the temperature $M_{d 30}$ is defined as the temperature range within which a 50\% $\gamma \rightarrow \alpha^{\prime}$ transformation can occur for a plastic deformation $\epsilon_{\mathrm{pl}}$ of $30 \%$. The $\mathrm{M}_{\mathrm{s}}$ and $\mathrm{M}_{\mathrm{d} 30}$ temperatures of the stainless steel fibers used in this study were empirically approximated using the models described by Eichelmann [21] and Angel [22], respectively, and were compared to those used in preceding studies $[18,23,24]$, which looked at different stainless steel types for their metastability.

\section{Materials and Methods}

\subsection{Material Properties}

The CFRP and MCFRP laminates were fabricated using Tenax® HTS-40 high-tenacity carbon fibers (Teijin Ltd., Chiyoda, Japan ) in a Cycom 977-2 epoxy matrix (Solvay, Brussels, Belgium, diameter $7 \mu \mathrm{m}$, area weight $135 \mathrm{~g} / \mathrm{cm}^{2}$ ). Stainless steel fibers of type DIN 1.4301 / AISI-304 with a diameter of $75 \mu \mathrm{m}$ were procured from Beakaert (Zwevegem, Belgium) and made up the metallic part of the MCFRPs. Table 1 summarizes the mechanical properties of the constituent materials of the composites.

Table 1. Selected properties of the carbon fibers, steel fibers and epoxy matrix.

\begin{tabular}{lccc}
\hline & Carbon Fiber & Stainless Steel Fiber & Epoxy Matrix \\
\hline Density $\left[\mathrm{g} / \mathrm{cm}^{3}\right.$ ] & 1.77 & $7.95 \pm 0.01$ & 1.31 \\
Tensile modulus [GPa] & $239 \pm 2.9$ & $190 \pm 9.2$ & 3.52 \\
Tensile strength [MPa] & $4121 \pm 755$ & $762 \pm 7.5$ & 81.40 \\
Failure strain [\%] & $1.55 \pm 0.24$ & $32 \pm 2.5$ & $\mathrm{n} / \mathrm{a}$ \\
Shear modulus [GPa] & 50 & $67 \pm 9$ & 1.30 \\
Poisson's ratio & 0.23 & 0.30 & 0.35 \\
Fiber diameter [ $\mu \mathrm{m}]$ & 7 & 75 & - \\
\hline
\end{tabular}

The deformation-dependent austenite-martensite transformation is highly dependent on the chemical composition of the steel, in particular on the carbon, nitrogen, nickel and chromium content. The constituents of the stainless steel used in this work were determined through spectral analysis following the ASTM E 1019 and ASTM E 572 standards and are shown in Table 2. 
Table 2. The chemical constituents of the $75 \mu \mathrm{m}$ thick stainless steel fibers.

\begin{tabular}{lccccccc}
\hline Element & $\mathrm{C}$ & $\mathrm{Si}$ & $\mathrm{Mn}$ & $\mathrm{P}$ & $\mathrm{S}$ & $\mathrm{Nb}$ & $\mathrm{Ti}$ \\
wt.\% & 0.026 & 0.32 & 1.57 & 0.011 & 0.009 & 0.016 & 0.004 \\
\hline Element & $\mathrm{Mo}$ & $\mathrm{Cu}$ & $\mathrm{Ni}$ & $\mathrm{Cr}$ & $\mathrm{V}$ & $\mathrm{N}_{2}$ & $\mathrm{Fe}$ \\
wt.\% & 0.336 & 0.31 & 10.99 & 18.33 & 0.11 & 0.036 & 67.9 \\
\hline
\end{tabular}

\subsection{Laminate Fabrication}

The CFRP laminates were fabricated using 17 unidirectional plies stacked in the following layup,

$$
\left[0^{\circ} / 90^{\circ} / 45^{\circ} /-45^{\circ} / 45^{\circ} /-45^{\circ} / 90^{\circ} / 0^{\circ} / 90^{\circ} / 0^{\circ} / 90^{\circ} / 45^{\circ} /-45^{\circ} / 45^{\circ} /-45^{\circ} / 90^{\circ} / 0^{\circ}\right] \text {. }
$$

The CFRP stack was consolidated through a one-hour dwell at $135^{\circ} \mathrm{C}$, followed by a three-hour cure at $180^{\circ} \mathrm{C}$ at a heating and cooling rate of $2{ }^{\circ} \mathrm{C} / \mathrm{min}$. A pressure of $6.5 \mathrm{bar}$ was applied from the start to the end of the curing process. This dwell time causes a decrease in the resin viscosity to nearly its minimum, leading to better resin distribution through the stack and allowing longer times for entrapped air to escape. The final dimensions of the laminate plates were measured at $350 \times 350 \times 2 \mathrm{~mm}^{3}$ and a CF fiber content of $60 \mathrm{vol} . \%$. Figure $2 \mathrm{a}$ shows the layup alongside an image of the longitudinal CFRP sample cross-section.

The MCFRP laminates were fabricated using the same CF layup except for the two $0^{\circ}$-plies on the periphery. These were replaced by four steel fiber layers on each side in the $\left[90^{\circ} / 90^{\circ} / 0^{\circ} / 0^{\circ}\right]$ directions. These metallic plies were fabricated in cooperation with GKD-Gebr. Kufferath AG (Düren, Germany) into quasi-unidirectional weaves with polyethersulfone (PES) filaments $(\phi=90 \mu \mathrm{m})$ in the warp direction approximately every $50 \mathrm{~mm}$, as shown in Figure 3a. The weaves were impregnated with the Cycom 977-02 (area weight: $40 \mathrm{~g} / \mathrm{cm}^{2}$ ) resin film.
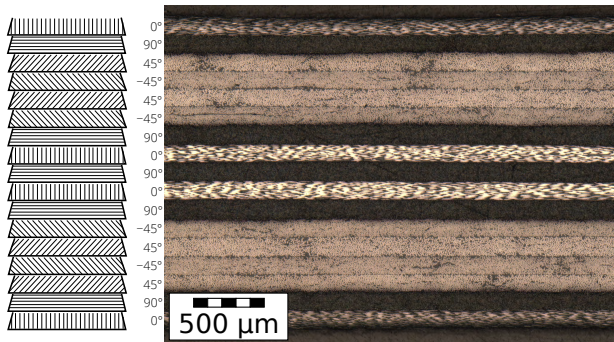

(a)
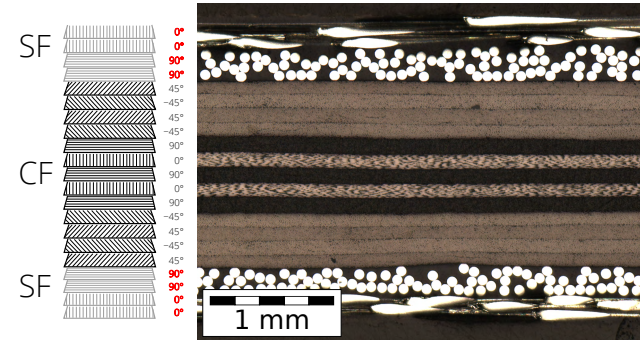

(b)

Figure 2. (a) The CFRP laminate layup illustrated schematically next to a light-microscopic image of a sample in the longitudinal direction. (b) A schematic depiction of the MCFRP laminate layup alongside a microscopic image of a sample, with the eight peripheral layers composed of stainless steel fibers (SF).

Figure $3 b$ illustrates the fabrication process for the steel plies. After weaving the PES filaments, the fibers were fixed onto a frame and stretched to ensure a parallel fiber orientation. The PES fibers were then dissolved by heating to $250^{\circ} \mathrm{C}$, followed by the pressing and curing of resin films on both sides of the ply at $130^{\circ} \mathrm{C}$. The hardened plies were then cut to the required size and used on the top and bottom layers using the aforementioned autoclave process. The MCFRP laminate plates were fabricated in the same lateral size as that of the CFRP plates, with a thickness of $2.4 \mathrm{~mm}$ and CF and steel-fiber (SF) contents of $49 \mathrm{vol} . \%$ and $18 \mathrm{vol} . \%$, respectively. The layup and longitudinal cross-section for MCFRP is shown in Figure 2b. 


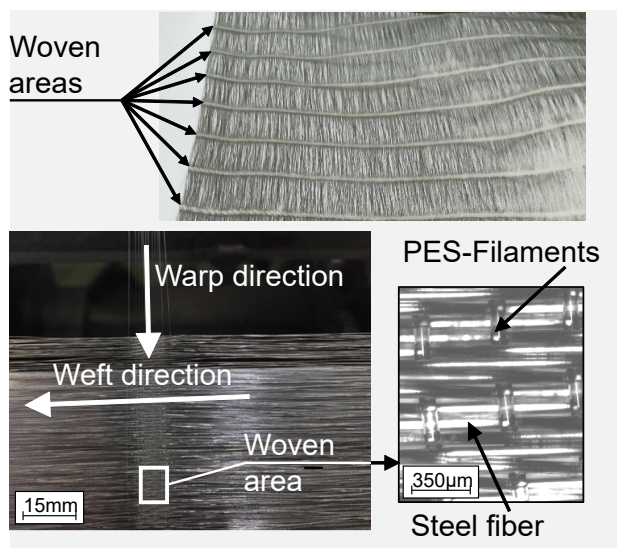

(a)

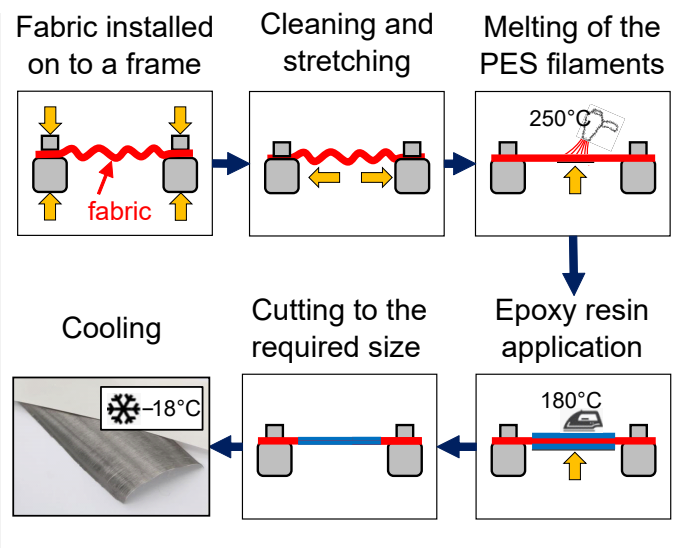

(b)

Figure 3. (a) Images of the steel fiber woven with PES filaments in the warp direction. (b) A schematic depiction of the preparation of the steel-fiber weaves for the fabrication of MCFRPs. The fibers are stretched on to a frame and heated to $250^{\circ} \mathrm{C}$ to melt the PES filaments. After cooling to $-18^{\circ} \mathrm{C}$ and cutting to the required dimensions, the plies were impregnated with epoxy at $180^{\circ} \mathrm{C}$.

The laminate plates were cut into dog-bone shaped samples using a Daetwyler Microwaterjet (Bleienbach, Switzerland), measuring $160 \mathrm{~mm}$ in length with a grip-area of $20 \times 35 \mathrm{~mm}$ as illustrated in Figure $4 \mathrm{a}$. The middle section of the samples $(R=139 \mathrm{~mm})$ resulted in a width of $5 \mathrm{~mm}$ at the center.

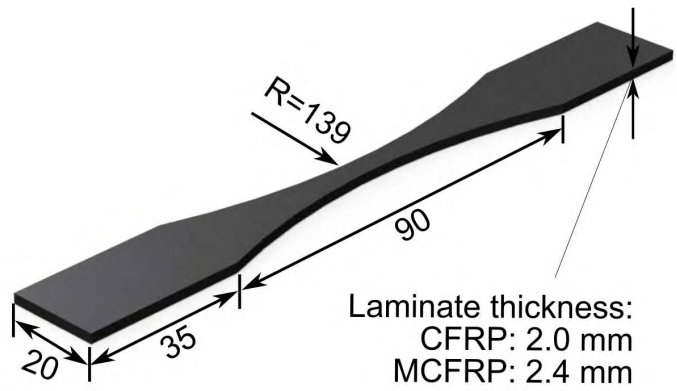

(a)

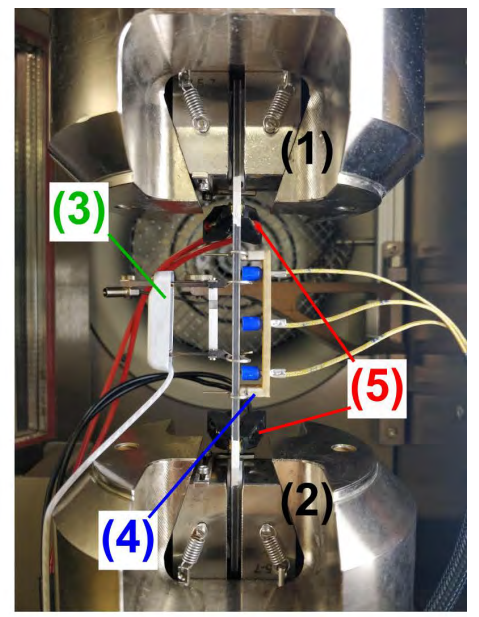

(b)

Figure 4. (a) A schematic depiction of the dog-bone shaped samples fabricated using CFRP and MCFRP for this work. All measurements are in $\mathrm{mm}$. The radial central region of the sample resulted in a width of $5 \mathrm{~mm}$ in the middle of the sample. (b) An image of a fully-equipped MCRFRP sample for fatigue testing. The sample is clamped in the servohydraulic test-machine between (1) and (2). The setup is additionally equipped with a strain-gauge (3), three thermocouples mounted onto a holder (4) and a four-point resistance measurement setup (5).

The samples were coated with the SilverDAG 1415 electrically conductive paste (Plano, Wetzlar, Germany) to reduce the contact resistance for the four-point resistance electrical measurements. Additionally, $0.5 \mathrm{~mm}$-thick glass-fiber composite tabs were adhered to the grip area of the samples using epoxy to electrically isolate the sample from the rest of the test setup and to ensure a uniform clamping force during the experiments.

\subsection{Experimental Setup}

The CFRP and MCFRP samples were tested under tensile and fatigue conditions at three different temperatures; $-55,25$ (RT) and $120^{\circ} \mathrm{C}$. Tensile tests were used to determine 
the ultimate tensile strength of the samples, based upon which the fatigue tests were carried out. Fatigue testing under increasing load-amplitude (ILA) conditions was carried out to gauge the materials' response to different loads at different temperatures.

Based on the failure stress amplitude and the plastic material response during the ILA tests, a set of tests under constant load-amplitude (CLA) were performed to develop $\mathrm{SN}$-curves for both laminates at each of the aforementioned temperatures. To analyze the fracture behavior, interrupted constant load-amplitude (iCLA) tests were carried out, where the samples were microscopically imaged at various fatigue stages to evaluate the crack initiation and propagation under cyclical loading conditions.

The tensile and fatigue experiments were carried out on the Zwick/Roell HC-25 servohydraulic testing machine (Ulm, Germany). Force and strain measurements were taken using a $25 \mathrm{kN}$ load cell and a clip-on strain gauge with a $\pm 2.5 \mathrm{~mm}$ range. The non-RT experiments were performed with the samples enclosed inside a temperature chamber from the same manufacturer. This chamber was heated to $120^{\circ} \mathrm{C}$ using its internal heater or cooled down to $-55^{\circ} \mathrm{C}$ connected to an external liquid nitrogen $\left(\mathrm{LN}_{2}\right)$ tank, which the chamber was able to control using a valve.

All fatigue tests were performed at a stress ratio $R=0.1$ at a frequency of $5 \mathrm{~Hz}$, except for the experiments at $-55^{\circ} \mathrm{C}$, which were carried out at $10 \mathrm{~Hz}$ due to the volume limitations of the available $\mathrm{LN}_{2}$ tank. For tests at -55 and $120^{\circ} \mathrm{C}$, the samples were held for $30 \mathrm{~min}$ after the test temperature was attained to ensure temperature homogeneity over the whole sample. Cyclical measurements of force, displacement, stress and strain were recorded using the testing machine's software, testXpert $R$. These yielded the total strain-amplitude $\epsilon_{\mathrm{a}, \mathrm{t}}$ and stiffness trends shown in the results and were recorded for each test up to the sample failure at the stress-amplitude $\sigma_{\mathrm{a}, \mathrm{f}}$ and the corresponding loading cycle $\mathrm{N}_{\mathrm{f}}$.

Additional sensors were incorporated into the test setup to measure the sample temperature and electrical resistance during the experiments. Three type $\mathrm{K}$ thermocouples were used to observe changes in the sample's surface temperature due to fatigue and fractures. The difference of the central thermocouple's $\left(\mathrm{TC}_{2}\right)$ reading, which is situated in the region undergoing fatigue damage, and the average of the temperature of the upper and lower thermocouples $\left(\mathrm{TC}_{1}\right.$ and $\mathrm{TC}_{3}$, respectively), situated $20 \mathrm{~mm}$ from $\mathrm{TC}_{2}$, yielded the temperature difference $(\Delta \mathrm{T})$ of the sample,

$$
\Delta T=T C_{2}-\frac{T C_{1}+T C_{3}}{2} .
$$

The stiffness degradation of the samples was obtained by taking the normalized ratio of the upper and lower limits of the applied force $F$ and measured strain $\epsilon$ for each loading cycle $N$ using

$$
\text { Stiffness degradation }=\left|\left(\frac{F_{\max }-F_{\min }}{\epsilon_{\max }-\epsilon_{\min }}\right)_{N}-\left(\frac{F_{\max }-F_{\min }}{\epsilon_{\max }-\epsilon_{\min }}\right)_{N=0}\right|
$$

A four-point resistance measurement setup was realized using two gold-plated clamps attached to the sample throughout the tests to measure the change in electrical resistance $\triangle \mathrm{R}$. For MCFRP, the martensite content was measured and compared before and after the relevant experiments using the Fischer FMP-30 ferritscope (Helmut-Fischer, Sindelfingen, Germany). The temperature, resistance and martensite readings were interfaced with an in-house data-logger developed in the LabVIEW ${ }^{\circledR}$ programming environment.

\section{Results and Discussion}

\subsection{Tensile Tests}

The CFRP and MCFRP samples were tested for their monotonic properties at a rate of $50 \mathrm{~N} / \mathrm{s}$ at $-55,25$ and $120^{\circ} \mathrm{C}$. Five CFRP and MCFRP samples were tested at each temperature. The measured ultimate tensile strengths are shown in Figure 5.

The CFRP samples in Figure 5a show higher ultimate tensile strengths (UTS) compared to their MCFRP counterparts. This is a result of the laminate layup difference between 
the two composites with the CFRP laminate carrying two more $0^{\circ} \mathrm{CF}$ layers. The UTS for both laminates can be seen to decrease with increasing temperatures. In Figure 5b, no pronounced difference in the plasticity and the total strain at failure was observed between the two laminates. The average UTS values observed for each laminate and temperature were used as the upper boundary condition for the increasing load-amplitude fatigue tests.

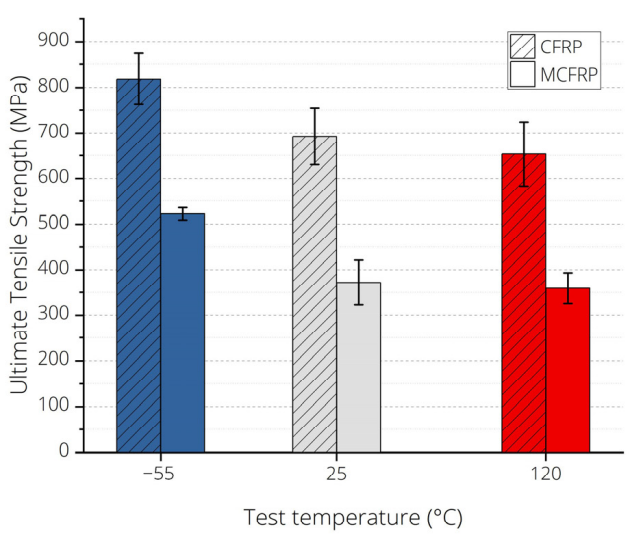

(a)

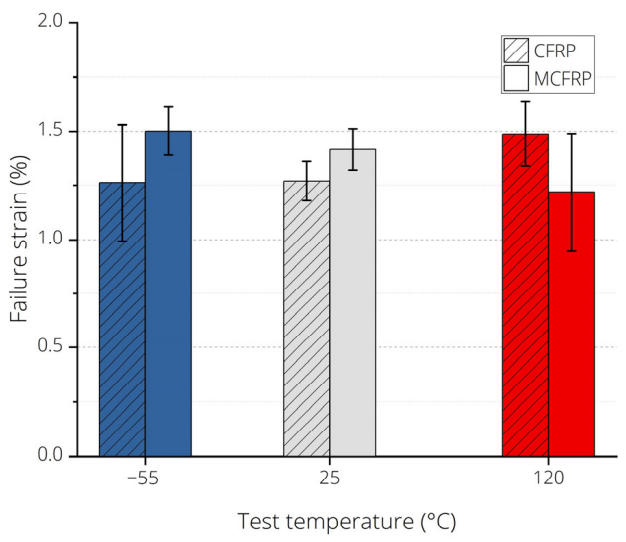

(b)

Figure 5. Results from the quasi-static tests, (a) the ultimate tensile strength (UTS) and (b) the failure strain, of the CFRP and MCFRP samples at the three test temperatures.

\subsection{Increasing Load-Amplitude (ILA) Tests}

Increasing load-amplitude tests were performed for both composites at each temperature point using the data obtained from the monotonic experiments. Each ILA test was carried out at a step-wise increasing stress-amplitude $\Delta \sigma_{\mathrm{a}}$ of $5 \mathrm{MPa}$ every $5 \times 10^{3}$ to $1 \times 10^{4}$ cycles per step $(\Delta \mathrm{N})$. The experiments at RT and $120^{\circ} \mathrm{C}$ were done at a loading frequency of $5 \mathrm{~Hz}$, whereas the $-55^{\circ} \mathrm{C}$ tests were performed at $10 \mathrm{~Hz}$. The upper limit of $\sigma_{\mathrm{a}}$ was set to the ultimate tensile strength (UTS) observed for each material and temperature.

Figures 6 and 7 show the characteristic curves from ILA tests for both laminates. Both follow a step-wise increase in the stress-amplitude with a corresponding increase in the total strain-amplitude, indicated in the blue curves, leading to different stiffness degradation behaviors, shown in yellow. At all three test temperatures, the CFRPs (Figure 6) show no degradation until after the halfway point of the experiment $\left(\mathrm{N}>0.5 \cdot \mathrm{N}_{\mathrm{f}}\right)$, after which delaminations and fiber breakages cause a sharp decrease in the stiffness, leading to a brittle failure behavior.

In comparison, the stiffness degradation of the MCFRP (Figure 7) is more reactive to the step-wise increasing load-amplitudes, leading to a gradual degradation and a less brittle failure. This is due to the ductility of the steel fibers on the periphery of the MCFRP samples, which undergo plastic deformation in response to the applied cyclical load. The stiffness degradation can additionally be seen to be sharper at lower temperatures for the MCFRPs.

For the experiments at room temperature, the highest temperature increase $(\Delta \mathrm{T})$ for both the CFRP and MCFRP samples (Figures 6a and 7a, respectively) can be seen at the sample failure, as a result of the numerous fiber breakages at this point. Over the course of the tests, the $\Delta \mathrm{T}$ for the CFRP exhibits a change of up to $0.5^{\circ} \mathrm{C}$. In contrast, the MCFRP sample exhibits a progressive temperature increase with increasing load amplitudes, with $\Delta \mathrm{T}_{\max }$ reaching $1^{\circ} \mathrm{C}$ during the fatigue phase.

For the tests at $120^{\circ} \mathrm{C}$ (Figures $6 \mathrm{~b}$ and $7 \mathrm{~b}$ ) as well as those at $-55^{\circ} \mathrm{C}$ (Figures $6 \mathrm{c}$ and $7 \mathrm{c}$ ), the $\Delta \mathrm{T}_{\max }$ can be seen to remain within $\pm 1^{\circ} \mathrm{C}$ throughout the tests.

The electrical resistance behavior with fatigue, indicated in the green curves in Figures 6 and 7, confirm the slower fatigue onset of the MCFRPs. For the CFRP, the change in resistance was dependent on the damage done to the $0^{\circ} \mathrm{CF}$-layers at the center and the 
periphery of the samples (shown in Figure 2a) and can be seen to remain constant up until fiber breakages right before failure.

The $45^{\circ}$ and $90^{\circ} \mathrm{CF}$ layers did not contribute to the electrical resistance of the sample, as they provide no direct electrical contact between the terminals of the four-point resistance measurement setup (see Figure $4 b(5)$ ). The steel fibers in the MCFRPs, with an inherently lower electrical resistance than $\mathrm{CF}$, showed a gradual increase in resistance while undergoing plastic deformation. At RT and at $120^{\circ} \mathrm{C}$, a pronounced increase prior to failure can also be observed, arising due to fiber breakages.

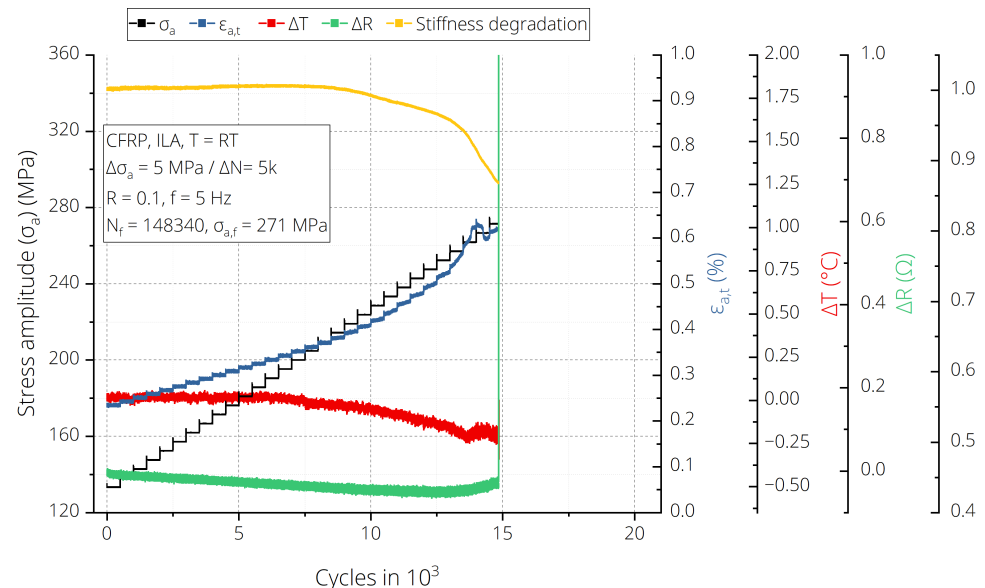

(a)
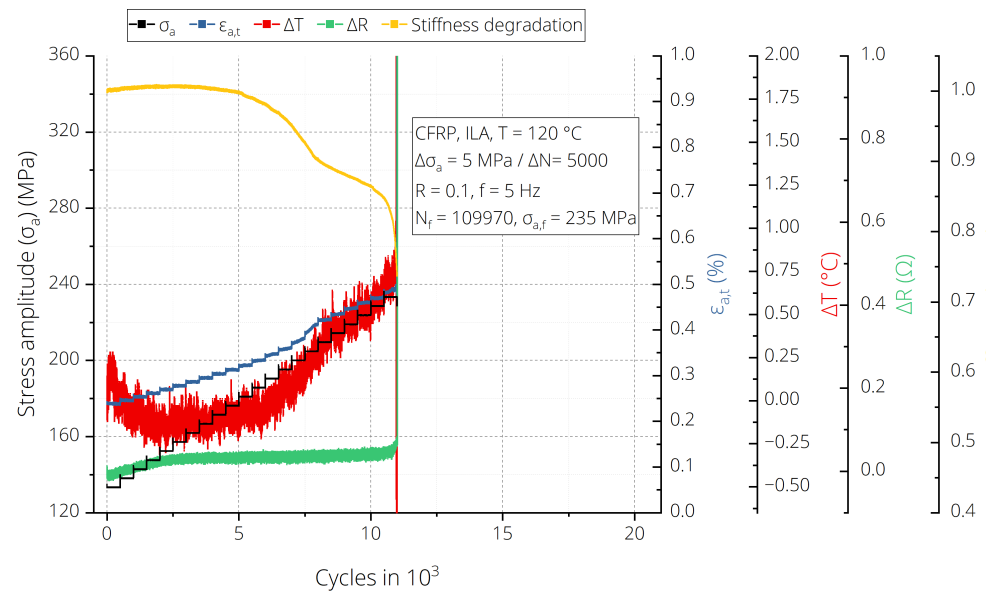

(b)

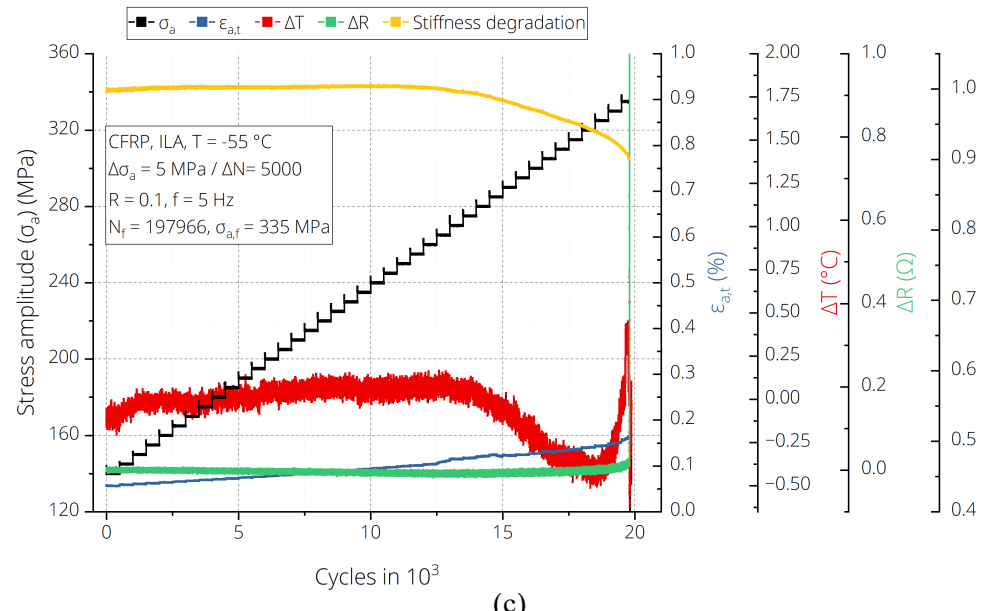

(c)

Figure 6. Fatigue behavior of the CFRP samples under increasing load-amplitude (ILA) conditions (a) at room temperature $/ 5 \mathrm{~Hz},(\mathbf{b})$ at $120^{\circ} \mathrm{C} / 5 \mathrm{~Hz}$ and (c) at $-55^{\circ} \mathrm{C} / 10 \mathrm{~Hz}$. 


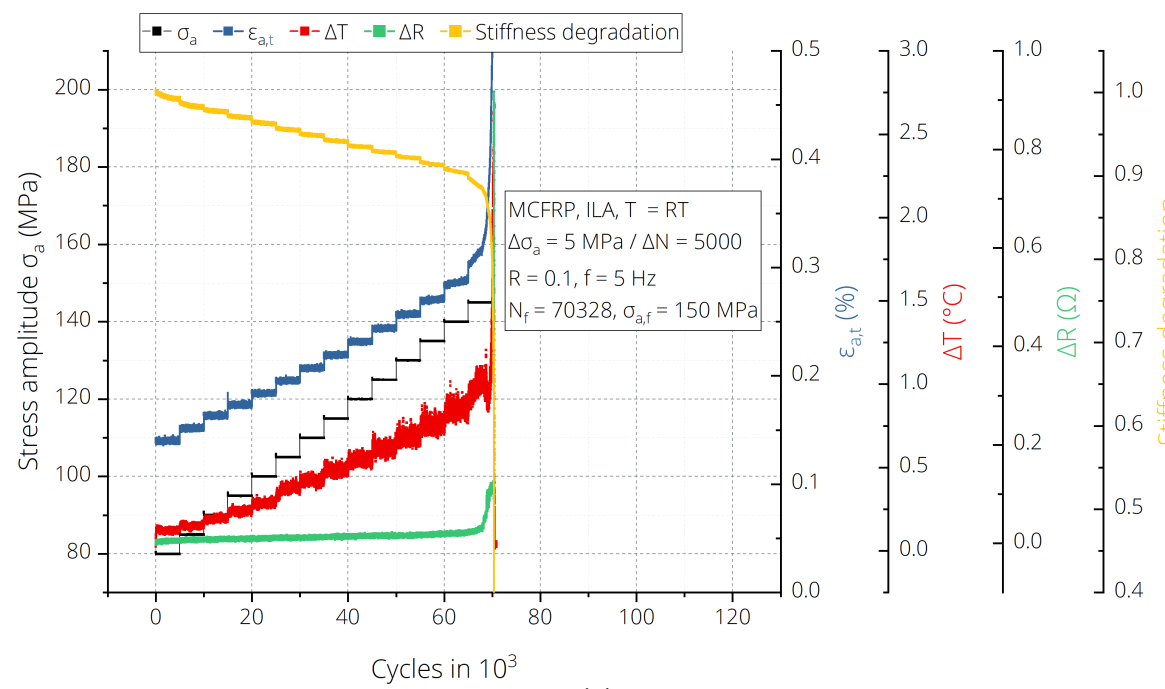

(a)

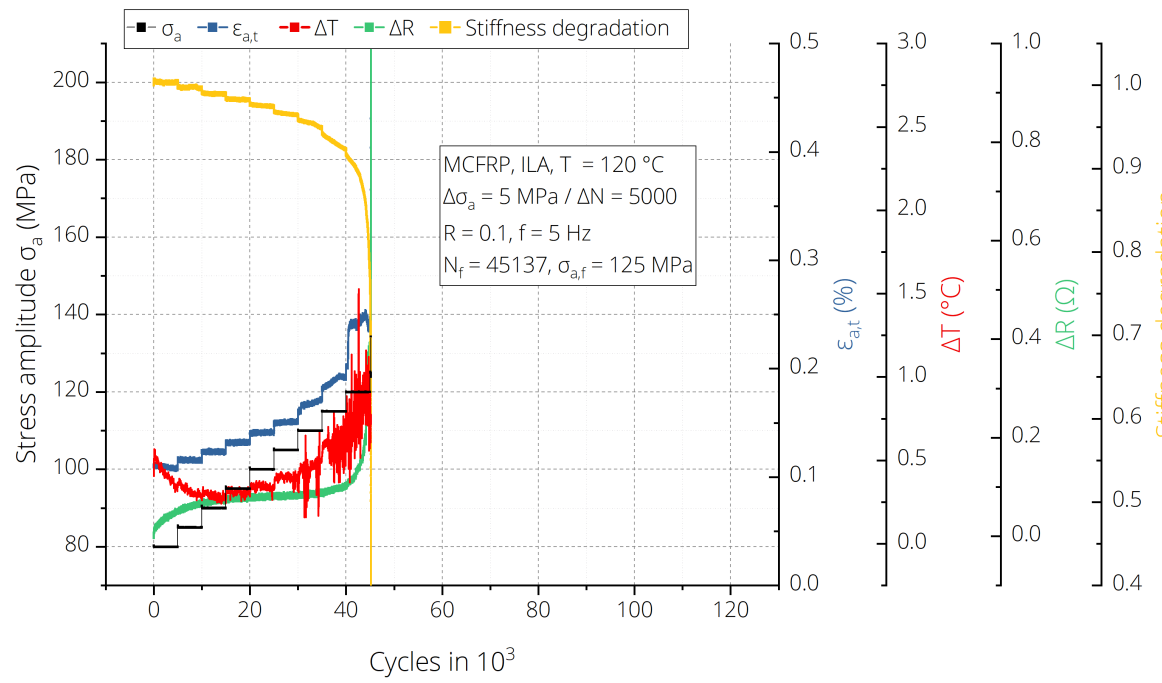

(b)

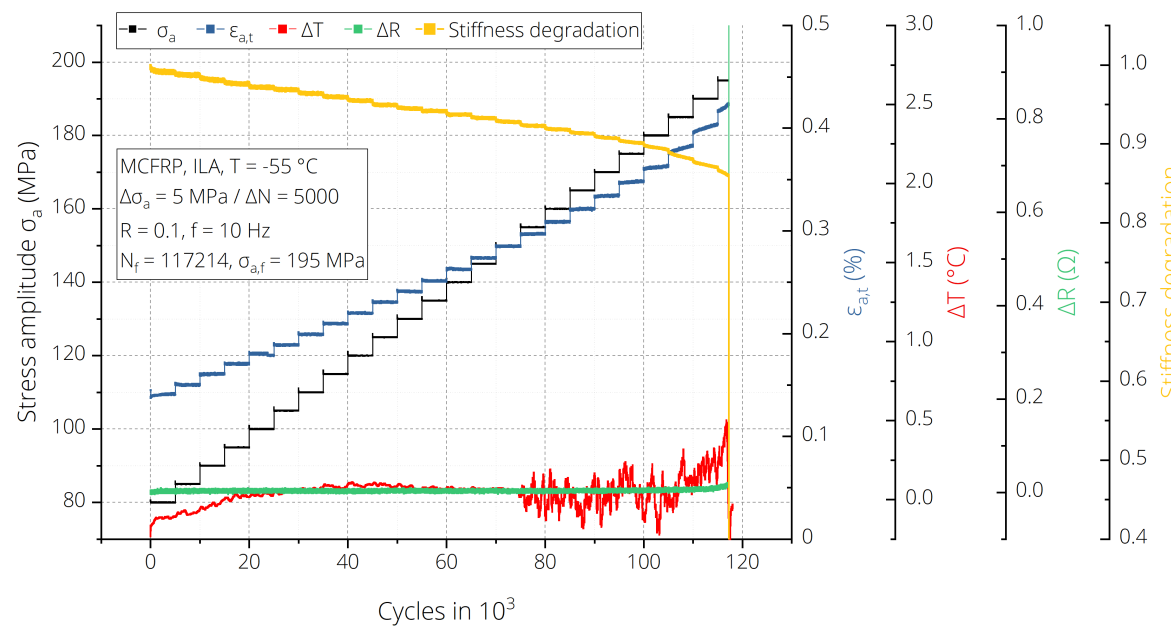

(c)

Figure 7. Fatigue behavior of the MCFRP samples under increasing load-amplitude (ILA) conditions (a) at room temperature $/ 5 \mathrm{~Hz},(\mathbf{b})$ at $120^{\circ} \mathrm{C} / 5 \mathrm{~Hz}$ and (c) at $-55^{\circ} \mathrm{C} / 10 \mathrm{~Hz}$. 


\subsection{CLA-Constant Load-Amplitude (CLA) Tests}

Experiments at constant load-amplitude were performed to investigate and compare the fatigue behavior, in the form of $\mathrm{SN}$-curves, for both composite materials. At each testtemperature, the cycles to failure $\left(\mathrm{N}_{\mathrm{f}}\right)$ were recorded against the load-amplitude alongside the temperature, electrical resistance and the pre- and post-failure martensite content. Figures 8 and 9 show representative results from CLA tests of CFRP and MCFRP samples, respectively, alongside the simultaneous recording of the change in the sample temperature $(\Delta \mathrm{T})$ and electrical resistance $(\Delta \mathrm{R})$ due to fatigue.

Under CLA conditions, both samples exhibited a three-phase stiffness degradation behavior. During the first stage, the samples undergo cyclic softening during the first $\approx 2 \%$ cycles. This softening was more pronounced at higher temperatures. The stiffness degradation curves of the CFRP samples (Figure 8a-c, yellow) show a steady decrease over the course of the tests, whereas the MCFRP samples (Figure 9a-c, yellow) exhibit a relatively flat region between the fatigue-softening and failure stages.

The strain-amplitude curves (blue) indicate the progressive damage done to the samples over the course of the tests. Both samples exhibit a more brittle behavior at lower temperatures, whereas the CFRP samples accumulate damage, arising due to layer delaminations and fiber breakage in the $45^{\circ}$ and $90^{\circ}$ layers relatively early when compared to their MCFRP counterparts (see Section 3.5). These total strain-amplitude and stiffness degradation trends hold for all three test temperatures and are an indicator for the better fatigue performance of MCFRPs.

The red curves show the change in temperature over the CLA tests. At $120^{\circ} \mathrm{C}$ (Figures $8 \mathrm{~b}$ and $9 \mathrm{~b}$ ), the $\Delta \mathrm{T}$ of both samples remains unchanged throughout the fatigue stage. At RT and $-55^{\circ} \mathrm{C}$, both samples showed a sharp increase in temperature at the start, followed by a gradual decrease back to the ambient temperature over the course of the experiment. The initial increase in temperature occurs during the cyclic-softening stage and is more pronounced at $-55^{\circ} \mathrm{C}$ due to accumulation of internal stresses during the cool-down phase before the samples are cyclically loaded.

The electrical resistance (green) curves for both sample types follow the expected trend seen in the ILA tests. The resistance of the CFRP samples, mainly dependent on the four $0^{\circ} \mathrm{CF}$-layers, remained relatively constant throughout the tests independent of test temperature, followed by an increase before failure, where fiber breakages start to occur. In contrast, plastic deformation of the steel fibers of the MCFRPs results in a gradual increase in $\Delta \mathrm{R}$ at $\mathrm{RT}$ and $120^{\circ} \mathrm{C}$. At $-55^{\circ} \mathrm{C}$, the change in resistance occurred chiefly at failure for both samples.

Figure 10 summarizes the results of CLA tests in form of SN-curves. Both sample types exhibit the expected inverse $\sigma_{\mathrm{a}}-\mathrm{N}$ trend up to the run-out $\left(\mathrm{N}=2 \times 10^{6}\right)$ as well as higher fatigue strengths at lower temperatures. The difference in the stress amplitudes between the CFRP and MCFRP arose due to the lower number of $0^{\circ} \mathrm{CF}$ layers in the MCFRP samples. Comparing the $-55^{\circ} \mathrm{C}$ run-out tests, the CFRP and MCFRP samples showed $30 \%$ higher fatigue strengths compared to their respective RT counterparts. 


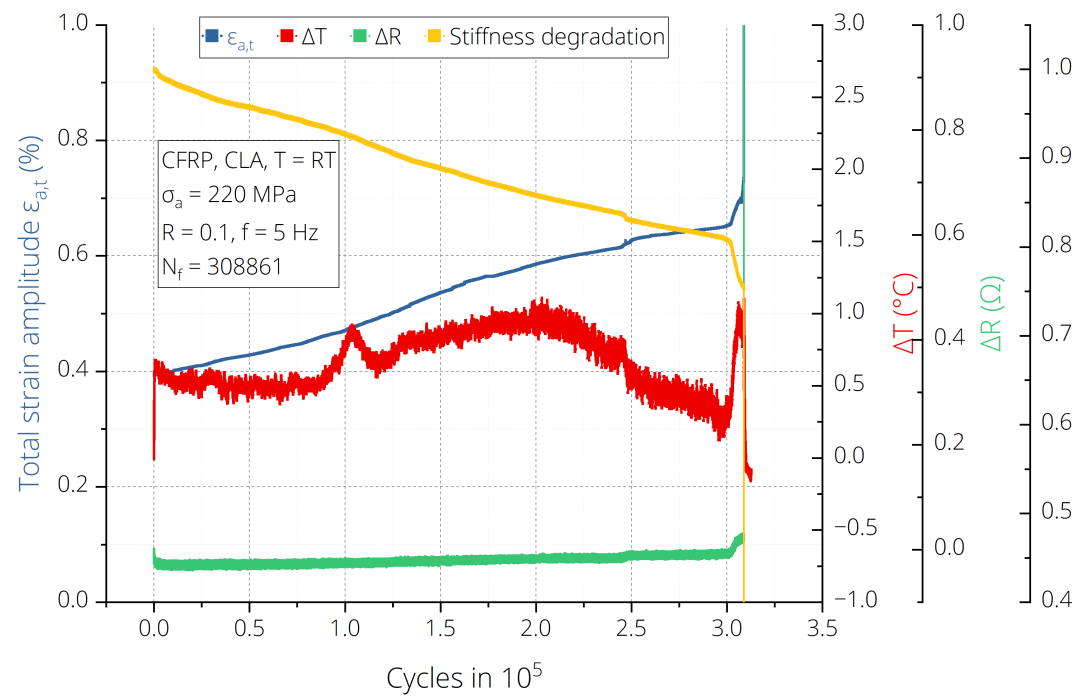

(a)

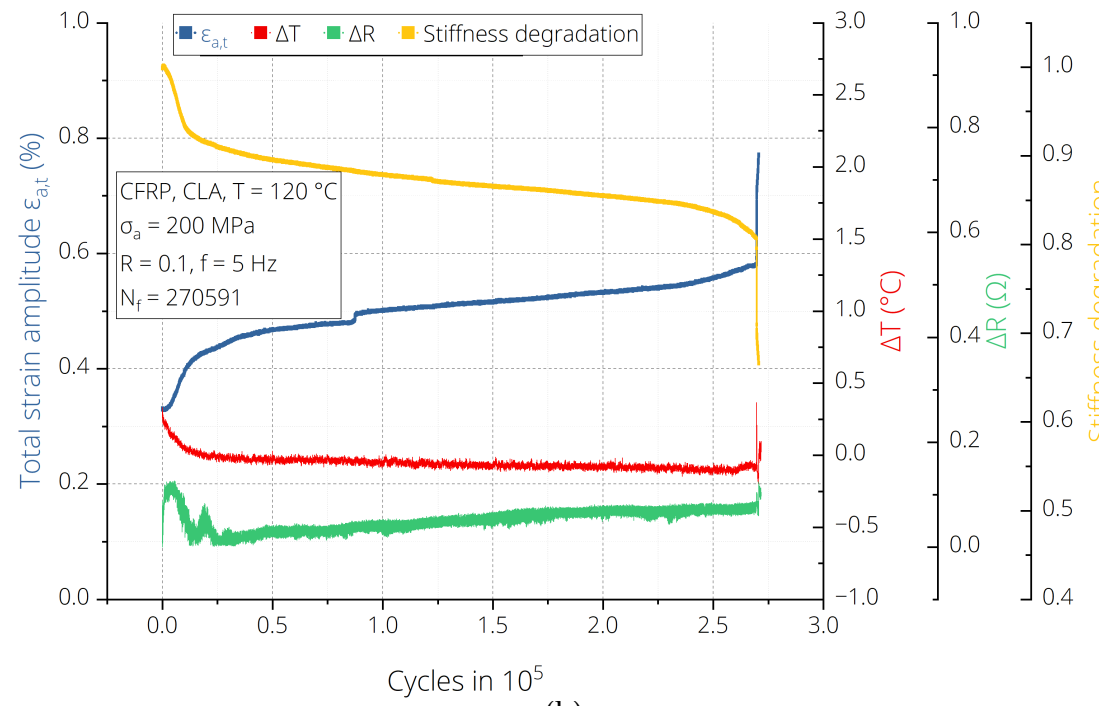

(b)

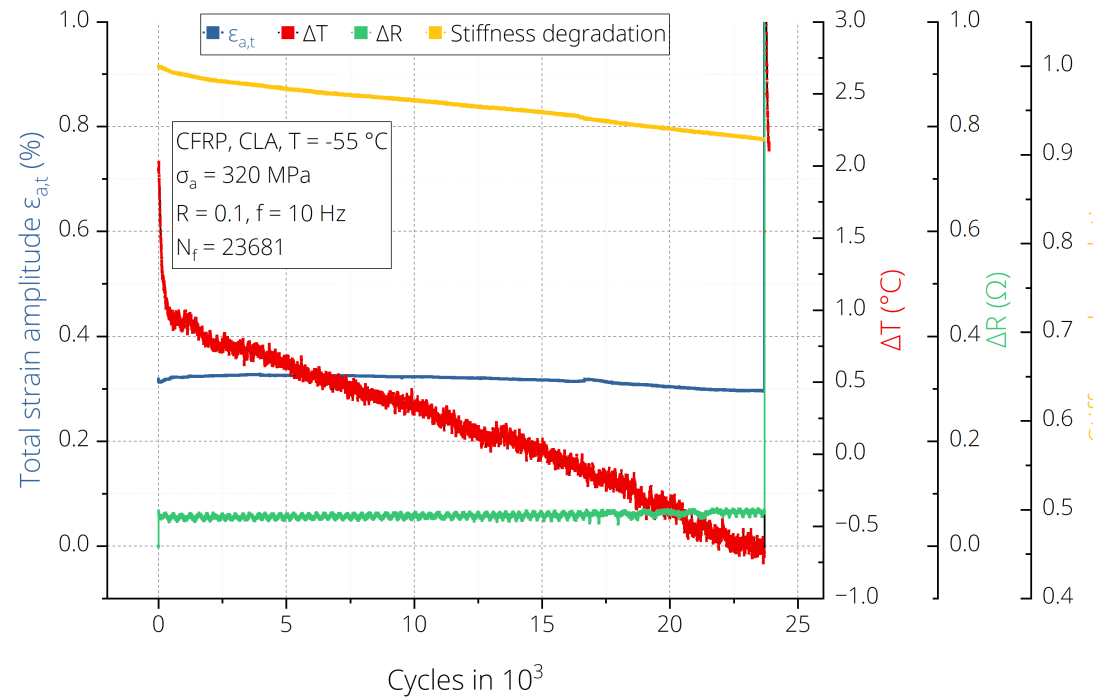

(c)

Figure 8. Representative behavior of the CFRP samples under constant load-amplitude (CLA) fatigue loading with $R=0.1$, tested at (a) room temperature $/ 5 \mathrm{~Hz},(\mathbf{b})$ at $120^{\circ} \mathrm{C} / 5 \mathrm{~Hz}$ and (c) at $-55^{\circ} \mathrm{C} / 10 \mathrm{~Hz}$. 


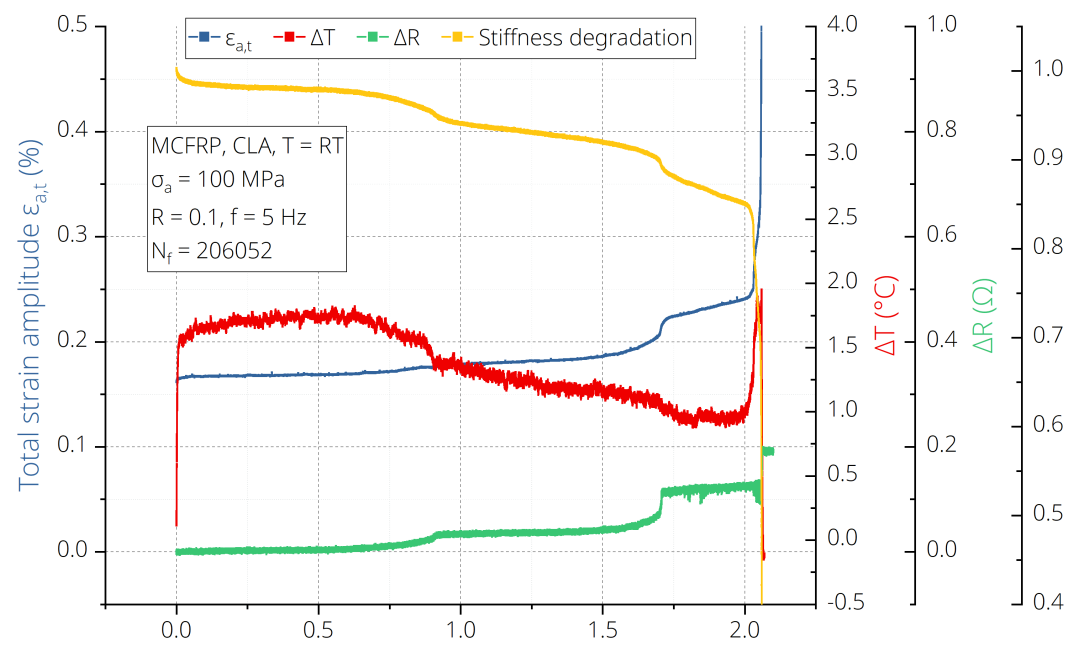

Cycles in $10^{5}$

(a)

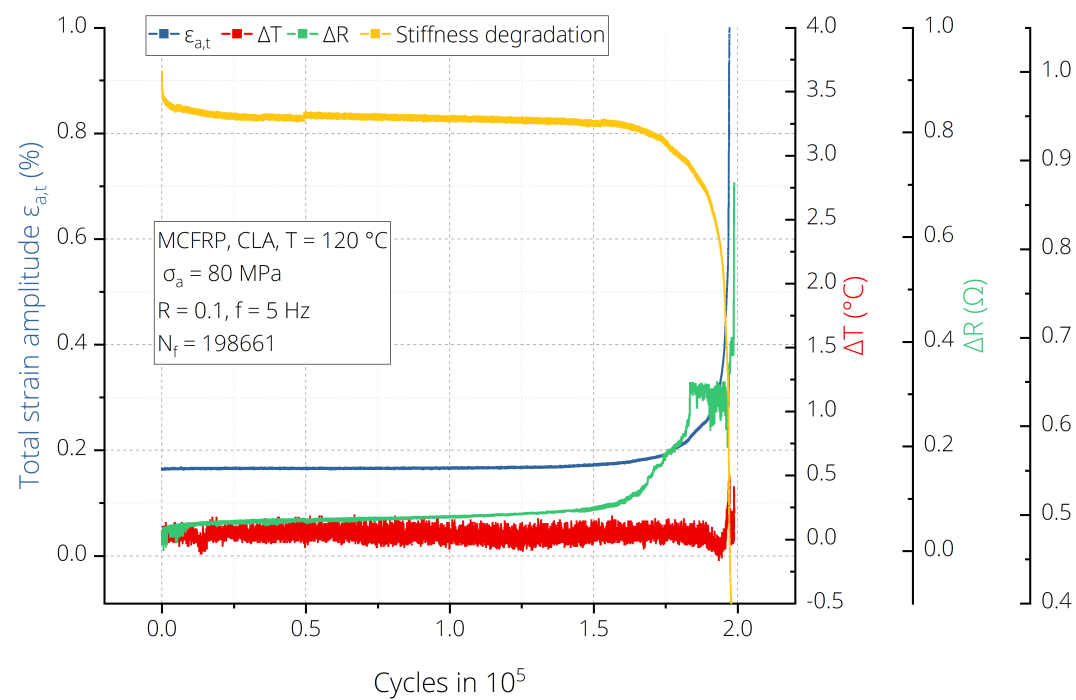

(b)

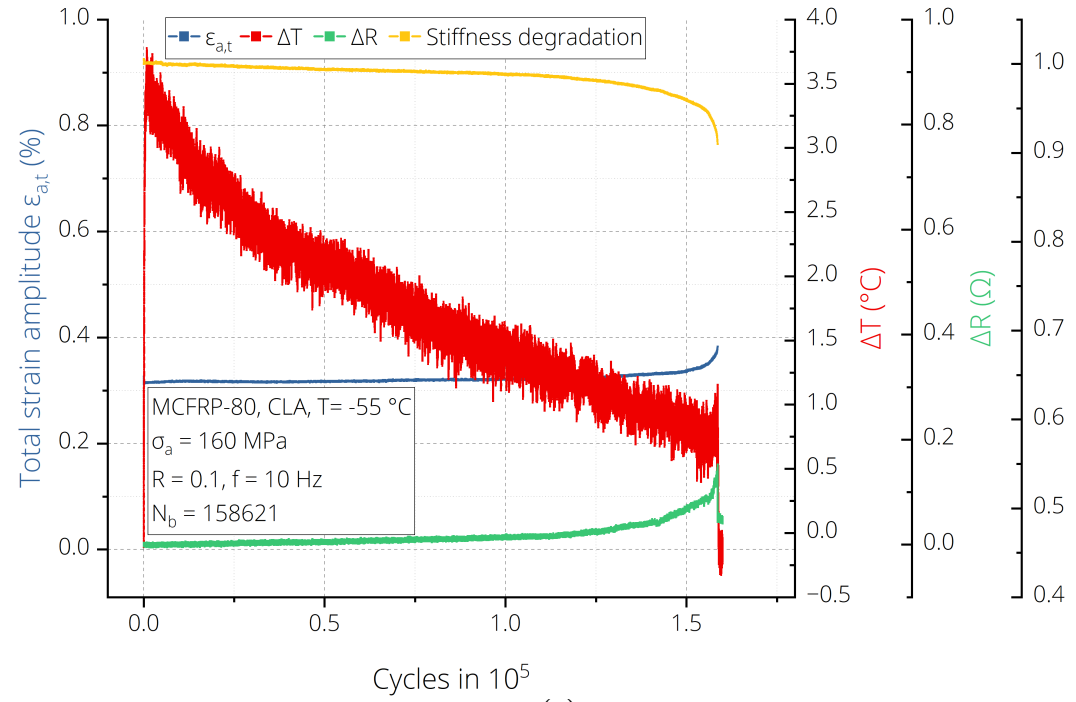

(c)

Figure 9. Representative behavior of the MCFRP samples under constant load-amplitude (CLA) fatigue loading with $R=0.1$, tested at (a) room temperature $/ 5 \mathrm{~Hz},(\mathbf{b})$ at $120^{\circ} \mathrm{C} / 5 \mathrm{~Hz}$ and (c) at $-55^{\circ} \mathrm{C} / 10 \mathrm{~Hz}$. 


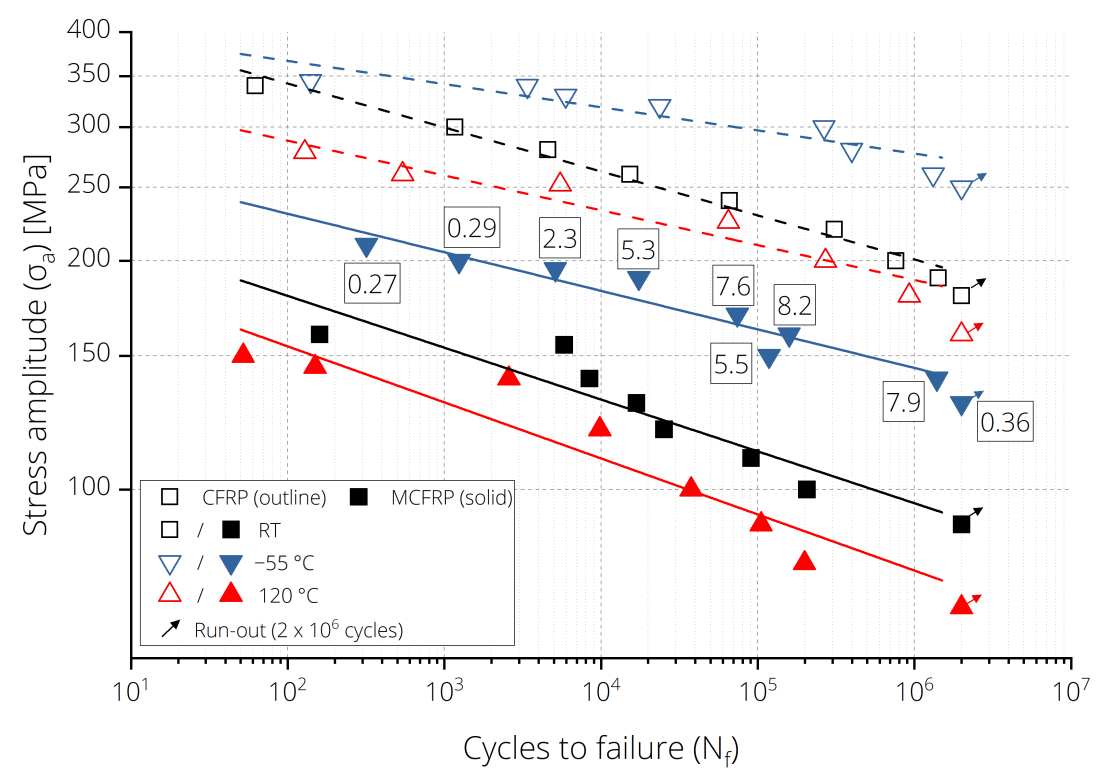

Figure 10. SN-Curves for the outline CFRP and the solid MCFRP laminates at black, square: RT, blue, inverted triangle: $-55^{\circ} \mathrm{C}$ and red, triangle: $120^{\circ} \mathrm{C}$, alongside their respective power-law relationships. The results shown with arrows did not fail up to $2 \times 10^{6}$ cycles. The annotations next to the $-55^{\circ} \mathrm{C}$ MCFRP results indicate the maximum martensite content measured post-failure for the corresponding experiments. The highest measured Fe- $\%$ was $8.2 \%$ for the experiment carried out at $\sigma_{\mathrm{a}}=160 \mathrm{MPa}$. No martensite content was observed at RT or at $120^{\circ} \mathrm{C}$.

\subsection{Metastability of the Steel Fibers}

The plasticity-induced martensitic phase transformation was measured for the MCFRP samples at the three test temperatures. No martensite content could be measured for all experiments at RT and $120^{\circ} \mathrm{C}$. The measured maximum martensite content observed at the end of each MCFRP CLA test at $-55^{\circ} \mathrm{C}$ is annotated in Figure 10. The Fe- $\%$ content measured in the low-cycle fatigue $(\mathrm{LCF})$ regime $\left(\mathrm{N}_{\mathrm{f}} \leq 1 \times 10^{4}\right)$ as well as for the run-out test $\left(\mathrm{N}=2 \times 10^{6}\right)$ is significantly lower than that of the high-cycle fatigue (HCF) tests, indicating a dual-dependency on the magnitude of the applied cyclical stress as well as a minimum number of cycles to failure.

The cumulative deformation of the $\mathrm{CF}$ and $\mathrm{SF}$ in the hybrid composite at a given stress-amplitude is the key factor governing the measured magnetic response. This can be seen for the sample tested at $\sigma_{\mathrm{a}}=130 \mathrm{MPa}$, which did not fail until the experimental upper limit of $2 \times 10^{6}$ cycles but exhibited a Fe-\% content significantly lower than that of the experiment performed at $\sigma_{\mathrm{a}}=140 \mathrm{MPa}$. This could be a result of the applied stressamplitude not being high enough to cause significant plastic deformation in the steel fibers. The highest $\mathrm{Fe}-\%$ was measured at $8.3 \%$ at $\sigma_{\mathrm{a}}=160 \mathrm{MPa}$ and $\mathrm{N}_{\mathrm{f}}=158,630$ cycles.

The room temperature stability of the austenite phase for the steel fibers used in this work can be explained through the Schaeffler diagram [25]. The steel fibers used here and in the preceding study [18] fall within the norms of the DIN standards for steels of type 1.4301 (AISI 304-L); however, their metastability was found to be significantly different at room temperature. Figure 11 illustrates and compares the metastability based on the measured chemical constituents of the fibers used in both studies.

It can be seen from Figure 11 that, although the steel fibers used in both studies fall under the constraints of the DIN 1.4301 standard, they differ significantly from each other in their nickel-equivalent content. This equivalency is dependent additionally on the carbon, manganese and nitrogen content found in the fibers. The chemical makeup of the fibers used in the prior study, marked red, lie on the boundary of the austenite and the martensite+austenite phase, which resulted in their metastability at room temperature and below. In contrast, the four fiber batches analyzed during this study had higher $\mathrm{Ni}$ equivalent content and lay on the boundary of the austenite and austenite+ferrite phases. 
This resulted in a more stable austenite phase at room temperature. The $\mathrm{M}_{\mathrm{s}}$ and $\mathrm{M}_{\mathrm{d} 30}$ temperatures for the current and preceding studies, based on the empirical models described by Eichelmann [21] the Angel [22], are compared in Table 3.

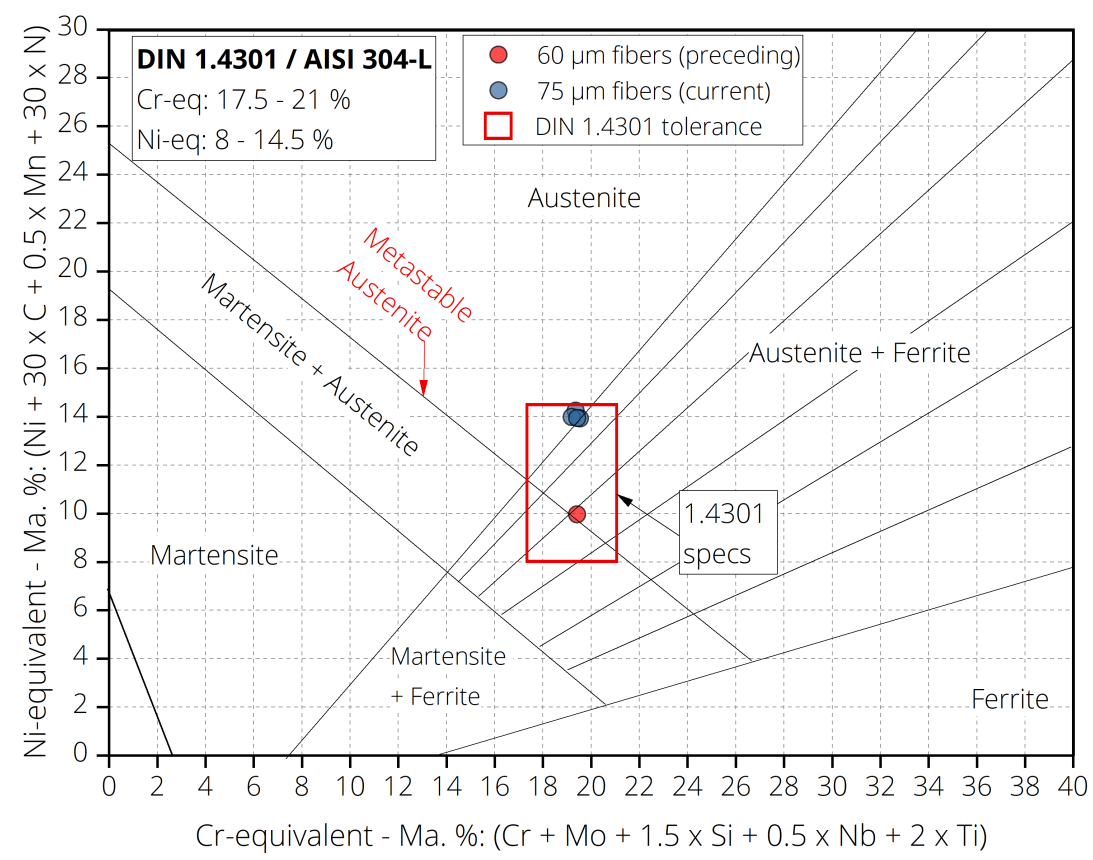

Figure 11. A comparison of the steel-fiber equivalent chemical formulations from four batches used in this work (blue), compared to those used in a preceding study (red) [18], using the Schaeffler phase-diagram [25]. The area within the red rectangle indicate the tolerances allowed for 1.4301 steel.

Table 3. A comparison of the $\mathrm{M}_{\mathrm{S}}$ and $\mathrm{M}_{\mathrm{d} 30}$ temperatures calculated through the Eichelmann [21] and Angel [22] empirical models.

\begin{tabular}{lccc}
\hline & $\begin{array}{c}\text { Fiber Diameter } \\
{[\boldsymbol{\mu m}]}\end{array}$ & $\begin{array}{c}\mathbf{M}_{\mathbf{s}} \text { (Eichelmann) } \\
{\left[{ }^{\circ} \mathrm{C}\right]}\end{array}$ & $\begin{array}{c}\mathbf{M}_{\mathrm{d} 30} \text { (Angel) } \\
{\left[{ }^{\circ} \mathrm{C}\right]}\end{array}$ \\
\hline Backe et al, 2018 [18] & $60 \mu \mathrm{m}$ & -38 & 47 \\
Current work & $75 \mu \mathrm{m}$ & -254 & -24 \\
\hline
\end{tabular}

Comparing the $\mathrm{M}_{\mathrm{d} 30}$ temperatures for both fibers, the metastability and the resulting deformation-induced martensitic phase transformation of the steel fibers from the previous study can be justified. For the fibers used in this work, the $M_{d 30}$ temperature of $-24^{\circ} \mathrm{C}$ resulted in a stable austenitic phase at room temperature. For this reason, the martensitic phase could be observed and measured solely for the tests carried out at $-55^{\circ} \mathrm{C}$. Future investigations can look at tailored steel compositions, which can ensure metastable characteristics at room temperature.

\subsection{Microscopy and Damage Evolution}

Interrupted CLA tests were performed to observe and compare the fatigue-failure mechanisms of the CFRP and MCFRP samples. The sample cross-sections were handpolished and imaged at different points under CLA conditions to observe the crack initiation, growth and failure. These experiments were performed at RT using load-amplitudes of $225 \mathrm{MPa}$ for the CFRP and $100 \mathrm{MPa}$ for the MCFRP samples, with an expected failure in the high-cycle fatigue (HCF) regime, between $\mathrm{N}=2-3 \times 10^{5}$ cycles. No additional sensors were mounted onto the sample during these tests to protect the imaging surfaces of the samples. Figures 12 and 13 show these results for CFRP and MCFRP, respectively. 

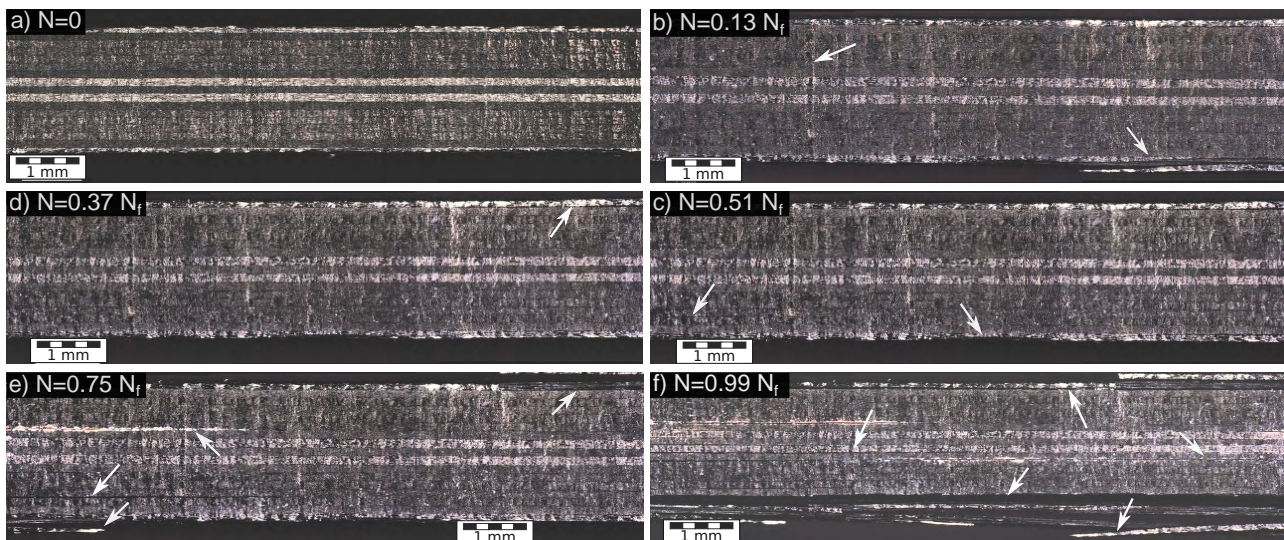

Figure 12. Microscopic images showing the damage evolution of a CFRP sample at various fractions of its fatigue life, indicated as a fraction of the cycles to failure $\left(\mathrm{N}_{\mathrm{f}}\right)$. Visible damage is shown using the white arrows.

The CFRP images shown in Figure 12 confirm the early damage initiation and propagation observed during the CLA tests. During the first stage of fatigue (imaged at $\mathrm{N}=13 \% \cdot \mathrm{N}_{\mathrm{f}}$ ), micro-cracks in the matrix can be observed alongside a delamination of part of the lowermost $0^{\circ}$-CF layer. At $\mathrm{N}=37 \% \cdot \mathrm{N}_{\mathrm{f}}$, a delamination of the uppermost $0^{\circ}$-CF-layer can be seen. This is followed by macro-delaminations of the $45^{\circ}$ layers at $75 \% \cdot \mathrm{N}_{\mathrm{f}}$. At this point, the effective sample cross-section is significantly reduced and the failure growth-rate accelerates. Shortly prior to failure $\left(\mathrm{N}=99 \% \cdot \mathrm{N}_{\mathrm{f}}\right)$, the outermost $0^{\circ}$-layers can be seen to have completely separated and suffered fiber breakage. At $\mathrm{N}_{\mathrm{f}}$, the core $0^{\circ}$-layers failed due to the highly reduced effective sample cross-section, leading to very high stresses on the remaining intact layers and a brittle failure.
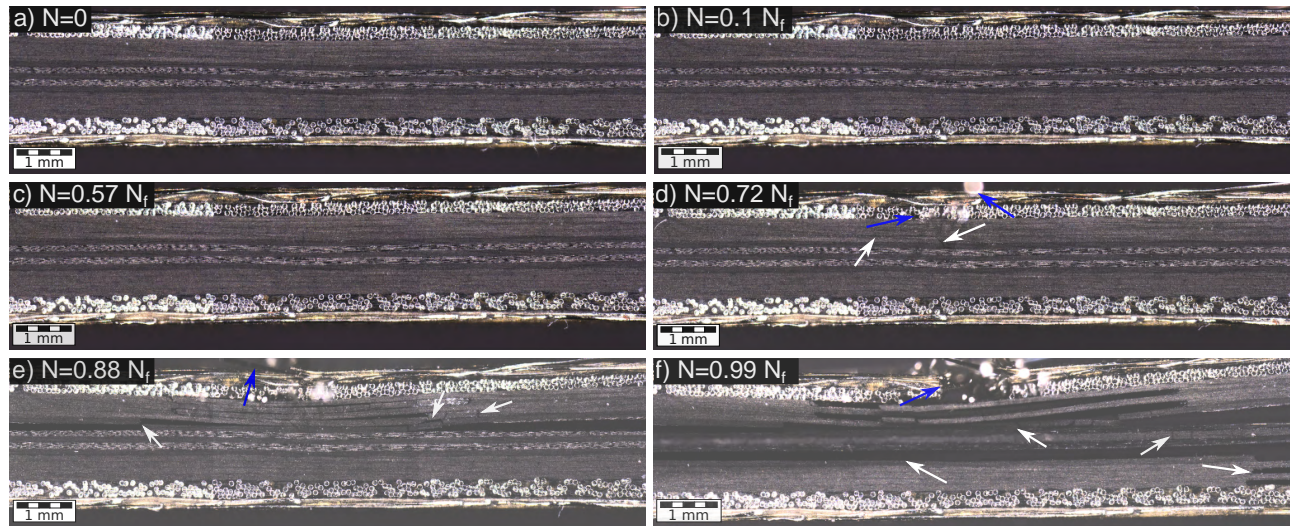

Figure 13. Micrographs showing the damage evolution of an MCFRP sample over its fatigue life. The white and blue arrows indicate damage observed in the carbon-fiber and steel-fiber layers, respectively.

The MCFRP failure behavior can be seen in Figure 13. During the first stage, no micro-cracks could be observed in the sample cross-section $(\mathrm{N}=10 \%)$, which confirms the significantly lower fatigue softening observed in these samples during the CLA tests. Visible damage can be observed only after the half-way mark of the fatigue life. This included CF layer delaminations as well as debonding and expulsion of some $90^{\circ}$ steel fiber layers at $\mathrm{N}=72 \% \cdot \mathrm{N}_{\mathrm{f}}$, shown as the blue arrows in Figure 13d. This point also marked the start of the accelerated damage phase, which resulted in several macro-delaminations and fiber breakages of the outermost steel-fiber layer as well as for the $\pm 45^{\circ}$ and $90^{\circ} \mathrm{CF}$ layers at $88 \% \cdot \mathrm{N}_{\mathrm{f}}$ (Figure13e). During the final stage before failure, several carbon-fiber breakages and a complete breakage of one of the $0^{\circ}$ steel-fiber layers can be seen.

The damage initiation and propagation differences between CFRP and MCFRP, observed during the tests under constant load-amplitudes can be confirmed in the microscopic 
images. The damage initiation and propagation occurs significantly later for the MCFRP due to the ductility of the steel fibers. When comparing the two composites right before failure $\left(\mathrm{N}=99 \% \cdot \mathrm{N}_{\mathrm{f}}\right)$, the MCFRPs exhibited greater damage in the form of delaminations and fiber breakages, which resulted in comparatively less brittle failure behavior.

\section{Conclusions and Outlook}

In this work, we explored the fatigue behavior of metal/carbon-fiber hybrid composites over a wide range of temperatures and compared the results to conventional carbon-fiber-reinforced polymers. Both composites were fabricated using the autoclave method with an identical epoxy matrix material. Tensile tests were performed to gauge the ultimate tensile strength of each composite, which was the basis for fatigue testing. The CFRP samples exhibited higher UTS due to more $0^{\circ}$ layers in the laminate.

Fatigue experiments were performed at a stress ratio $R$ of 0.1 at $5 \mathrm{~Hz}$ at $\mathrm{RT}$ and $120^{\circ} \mathrm{C}$ as well as at $10 \mathrm{~Hz}$ at $-55^{\circ} \mathrm{C}$. These included experiments with increasing loadamplitudes that showed increased strength at lower test temperatures. Both laminates showed increased cyclic softening at higher temperatures. A series of constant loadamplitude tests revealed the temperature behavior of the laminates over their fatigue properties up to $2 \times 10^{6}$ loading cycles.

At $-55^{\circ} \mathrm{C}$, the CFRP and MCFRP laminates were found to be, respectively, $30 \%$ and $40 \%$ more resilient compared to the $120^{\circ} \mathrm{C}$ experiments. Simultaneous measurement of temperature on the sample surface enabled the monitoring of temperature evolution due to fatigue and due to crack initiation and propagation under cyclical loading. Electrical resistance measurements showed that the plastic deformation and breakage of the steel fibers in the MCFRPs resulted in a simultaneous decrease in their electrical conductance.

The use of metastable austenitic steel fibers enabled the monitoring of the deformationdependent austenite-martensite phase transformation before and after the fatigue tests. At $120^{\circ} \mathrm{C}$ and at room temperature, no martensite content was detected. The samples tested at $-55{ }^{\circ} \mathrm{C}$ indicated a load- and fatigue-dependent relationship with the martensitic transformation, with up to $8.2 \%$ martensite measured in the HCF regime. These results are dissimilar when compared to the preceding study [18], which reported up to $12 \%$ martensite content at room temperature.

The difference can be explained through the $\mathrm{Cr}$ and $\mathrm{Ni}$-equivalent contents in the steel fibers through the Schaeffler diagram. Though both steel fibers qualify for the DIN standard 1.4301/AISI standard 304-L steel, the slightly higher $\mathrm{Ni}$ and $\mathrm{Cr}$ equivalent content of the fibers used in this study led to a more stable austenitic phase at room temperature and higher. To measure and correlate the degree of plastic deformation due to fatigue with the martensitic content in a practical application, steel fibers with a tailored chemical makeup, particularly by controlling the $\mathrm{Ni}, \mathrm{Cr}, \mathrm{N}$ and $\mathrm{C}$-content, will be required.

Author Contributions: Conceptualization, S.S., U.B. and F.B.; methodology, S.S. and F.B.; software, B.K.; validation, J.R. and B.K.; formal analysis, B.K.; investigation, B.K.; resources, S.S., F.B. and U.B.; data curation, B.K.; writing—original draft preparation, B.K.; writing—review and editing, J.R., S.S., F.B. and U.B.; visualization, B.K. and J.R.; supervision, F.B., U.B.; project administration, S.S., F.B. and U.B.; funding acquisition, F.B. and U.B. All authors have read and agreed to the published version of the manuscript.

Funding: This research was funded by the Deutsche Forschungsgemeinschaft (DFG), Project BA40736-2 and BR4262/2-1.

Acknowledgments: The authors would like to thank and gratefully acknowledge the financial support from the Deutsche Forschungsgemeinschaft (DFG), funding number 650202.

Conflicts of Interest: The authors declare no conflict of interest. 


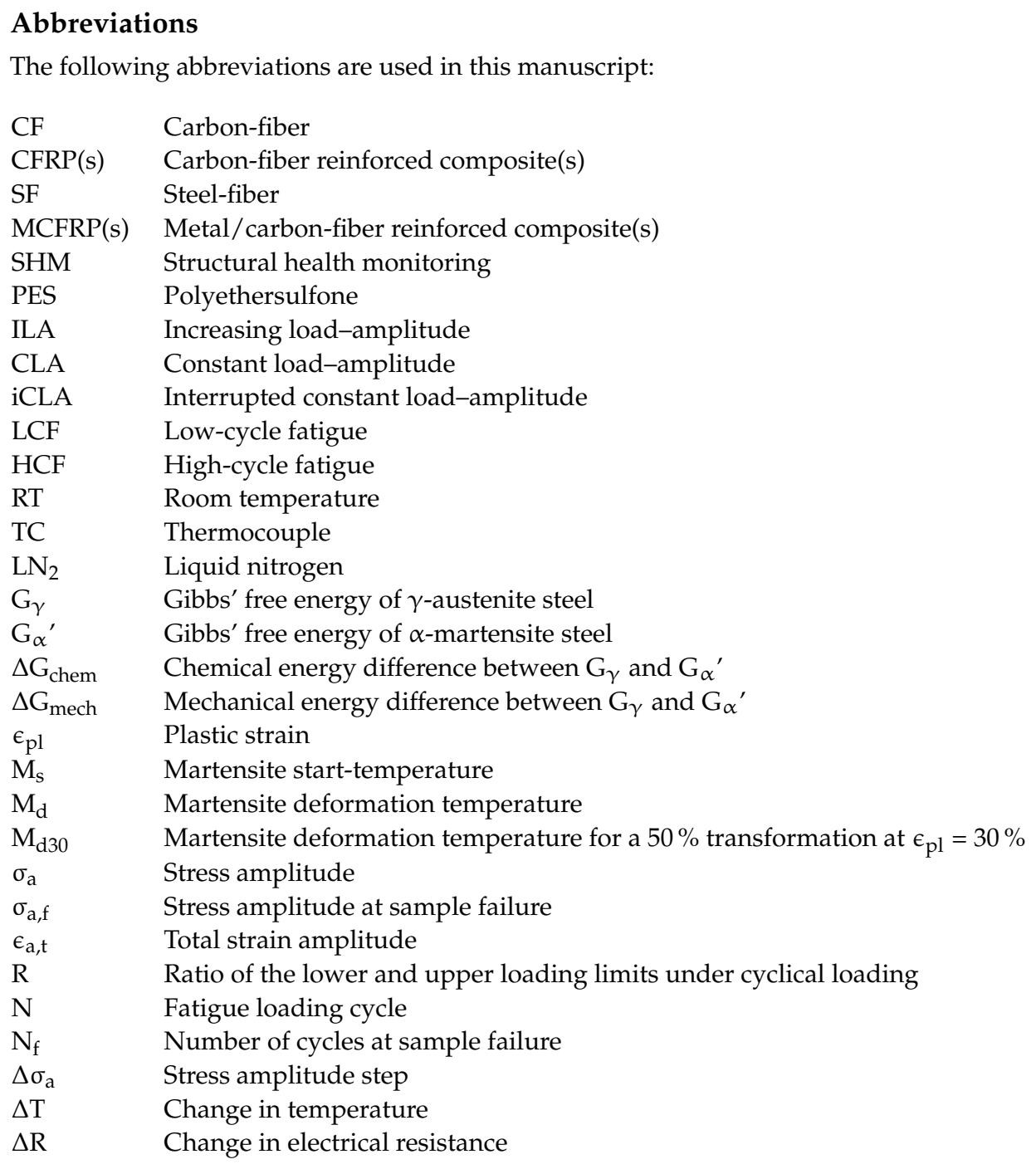

\section{References}

1. Breuer, U.P. Commercial Aircraft Composite Technology; Springer International Publishing: Berlin/Heidelberg, Germany, 2016; pp. 1-257. [CrossRef]

2. Spitalsky, Z.; Tasis, D.; Papagelis, K.; Galiotis, C. Carbon nanotube-polymer composites: Chemistry, processing, mechanical and electrical properties. Prog. Polym. Sci. 2010, 35, 357-401. [CrossRef]

3. Noll, A.; Friedrich, K.; Burkhart, T.; Breuer, U. Effective Multifunctionality of Poly(p-phenylene sulfide)Nanocomposites Filled with Different Amounts ofCarbon Nanotubes, Graphite, and Short Carbon Fibers. Polym. Compos. 2013, 34, 1405-1412. [CrossRef]

4. Czél, G.; Jalalvand, M.; Wisnom, M.R. Design and characterisation of advanced pseudo-ductile unidirectional thin-ply carbon/epoxy-glass/epoxy hybrid composites. Compos. Struct. 2016, 143, 362-370. [CrossRef]

5. Czél, G.; Jalalvand, M.; Wisnom, M.R.; Czigány, T. Design and characterisation of high performance, pseudo-ductile allcarbon/epoxy unidirectional hybrid composites. Compos. Part B Eng. 2017, 111, 348-356. [CrossRef]

6. Alderliesten, R.C.; Homan, J.J. Fatigue and damage tolerance issues of Glare in aircraft structures. Int. J. Fatigue 2006, $28,1116-1123$. [CrossRef]

7. Callens, M.G.; Gorbatikh, L.; Verpoest, I. Ductile steel fibre composites with brittle and ductile matrices. Compos. Part A Appl. Sci. Manuf. 2014, 61, 235-244. [CrossRef]

8. Callens, M.G.; Gorbatikh, L.; Bertels, E.; Goderis, B.; Smet, M.; Verpoest, I. Tensile behaviour of stainless steel fibre/epoxy composites with modified adhesion. Compos. Part A Appl. Sci. Manuf. 2015, 69, 208-218. [CrossRef]

9. Bañon, F.; Sambruno, A.; González-Rovira, L.; Vazquez-Martinez, J.M.; Salguero, J. A review on the abrasive water-jet machining of metal-carbon fiber hybrid materials. Metals 2021, 11, 164. [CrossRef]

10. Yao, Y.; Shi, P.; Qi, S.; Yan, C.; Chen, G.; Liu, D.; Zhu, Y.; Herrmann, A. Manufacturing and mechanical properties of steel-CFRP hybrid composites. J. Compos. Mater. 2020, 54, 3673-3682. [CrossRef]

11. Hao, X.; Nie, H.; Ye, Z.; Luo, Y.; Zheng, L.; Liang, W. Mechanical properties of a novel fiber metal laminate based on a carbon fiber reinforced Zn-Al alloy composite. Mater. Sci. Eng. A 2019, 740-741, 218-225. [CrossRef] 
12. Rizzo, F.; Pinto, F.; Meo, M. Development of multifunctional hybrid metal/carbon composite structures. Compos. Struct. 2019, 222, 110907. [CrossRef]

13. Yang, H.; Ng, B.C.; Yu, H.C.; Liang, H.H.; Kwok, C.C.; Lai, F.W. Mechanical properties study on sandwich hybrid metal/(carbon, glass) fiber reinforcement plastic composite sheet. Adv. Compos. Hybrid Mater. 2021, 1-8. [CrossRef]

14. Ammar, M.M.; Shirinzadeh, B.; Zhao, P.; Shi, Y. An approach for damage initiation and propagation in metal and carbon fiber hybrid composites manufactured by robotic fiber placement. Compos. Struct. 2021, 268, 113976. [CrossRef]

15. Hannemann, B.; Backe, S.; Schmeer, S.; Balle, F.; Breuer, U.P. Metal fiber incorporation in carbon fiber reinforced polymers (CFRP) for improved electrical conductivity. Mater. Werkst. 2016, 47, 1015-1023. [CrossRef]

16. Hannemann, B.; Backe, S.; Schmeer, S.; Balle, F.; Breuer, U.P. Hybridisation of CFRP by the use of continuous metal fibres (MCFRP) for damage tolerant and electrically conductive lightweight structures. Compos. Struct. 2017, 172, 374-382. [CrossRef]

17. Rehra, J.; Hannemann, B.; Schmeer, S.; Hausmann, J.; Breuer, U.P. Approach for an Analytical Description of the Failure Evolution of Continuous Steel and Carbon Fiber Hybrid Composites. Adv. Eng. Mater. 2019, 21, 1800565. [CrossRef]

18. Backe, S.; Balle, F.; Hannemann, B.; Schmeer, S.; Breuer, U.P. Fatigue properties of multifunctional metal- and carbon-fibrereinforced polymers and intrinsic capabilities for damage monitoring. Fatigue Fract. Eng. Mater. Struct. 2018, 42, 143-151. [CrossRef]

19. Warlimont, H.; Delaey, L.; Krishnan, R.V.; Tas, H. Thermoelasticity, pseudoelasticity and the memory effects associated with martensitic transformations. J. Mater. Sci. 1974, 9, 1545-1555. [CrossRef]

20. Tamura, I. Deformation-induced martensitic-transformation and transformation-induced plasticity in steels. Met. Sci. 1982, 16, 245-253. [CrossRef]

21. Eichelmann, G.H.; Hull, T. The effect of composition on the temperature of spontaneuos transformation of austenite to martensite in 18-8 type stainless steel. Trans. Am. Soc. Met. 1953, 45, 77-104.

22. Angel, T. Formation of Martensite in Austenitic Stainless Steels - Effects of Deformation, Temperature, and Composition. J. Iron Steel Inst. 1954, 177, 165-174.

23. Hahnenberger, F.; Smaga, M.; Eifler, D. Fatigue behavior and phase transformation in austenitic steels in the temperature range $-60^{\circ} \mathrm{C} \leq \mathrm{T} \leq 25^{\circ} \mathrm{C}$. Procedia Eng. 2011, 10, 625-630. [CrossRef]

24. Hahnenberger, F.; Smaga, M.; Eifler, D. Influence of $\gamma-\alpha^{\prime}$-phase transformation in metastable austenitic steels on the mechanical behavior during tensile and fatigue loading at ambient and lower temperatures. Adv. Eng. Mater. 2012, 14, 853-858. [CrossRef]

25. Schaeffler, A. Constitution Diagram for Stainless Steel Weld Metal. Met. Prog. 1949, 56, 680. 